\title{
Oxygen embolism after hydrogen peroxide irrigation during hip arthroscopy: a case report
}

\author{
Zhengwu Peng ${ }^{1}$, Hui Li ${ }^{1}$, Ziqin Cao ${ }^{1}$, Wenchao Zhang ${ }^{1}$, Hongxin $\mathrm{Li}^{1}$, Ruping Dai ${ }^{1}$, Lei Liu ${ }^{1}$, Xinzhan Mao ${ }^{1}$, \\ Daniel M. George ${ }^{2}$ and Tianlong Huang ${ }^{*^{*}}$ (D)
}

\begin{abstract}
Background: Hydrogen peroxide has been widely used in Orthopaedics including Orthopaedic oncology, trauma and joint surgeries. However, we encountered an oxygen embolism and myoglobinuria after hydrogen peroxide was used to irrigate a septic hip arthroscopically.

Case presentation: A 61-year-old male patient with right hip septic arthritis underwent an arthroscopic hip washout and debridement. During the operation, the surgeon used $100 \mathrm{ml}$ of $3 \%$ hydrogen peroxide to irrigate the joint cavity. Two minutes after irrigation, there was a transient decrease in oxygen saturation, heart rate and blood pressure, with significant subcutaneous emphysema around the wound. Concentrated urine was drained out $8 \mathrm{~h}$ after operation which resolved the following day. Post-operatively, the patient was managed in the intensive care unit for a pulmonary embolism and discharged without further complications.

Conclusion: Medical staff should be aware of the risk of oxygen embolism and be extremely careful when using hydrogen peroxide in patient care. Oxygen embolism following hydrogen peroxide use is rare, however, once encountered, it may bring serious consequences. Therefore, the use of hydrogen peroxide in closed spaces or arthroscopic procedures should be discontinued.
\end{abstract}

Keywords: Hydrogen peroxide, Hip arthroscopy, Oxygen embolism, Pyogenic arthritis

\section{Background}

Septic arthritis of the hip is when bacteria directly causes joint destruction and loss of function. In the past, surgeons would open the joint capsule, dislocate the femoral head if needed, and then irrigate and debride the joint thoroughly. However, during such an operation, the blood supply from the small concave artery and the ascending branch of medial circumflex femoral artery are easily damaged and serious complications encountered. Hip arthroscopy has increased in popularity since the 1970s, which has brought a new option for the treatment of septic arthritis. There have been reports of septic arthritis of the hip successfully treated via hip arthroscopy with good results [1-3].

\footnotetext{
* Correspondence: tianlong.huang@csu.edu.cn

${ }^{1}$ Department of Orthopaedics, the Second Xiangya Hospital, Central South

University, No.139 Middle Renmin Road, Changsha 410011, Hunan, China

Full list of author information is available at the end of the article
}

Hydrogen peroxide can rapidly decompose and release large amounts of oxygen and water after contact with the catalyst synthesized by organic tissues, such as the haem portion of haemoglobin. It is an effective oxidant, and is also a commonly used bactericide, hemostatic agent and surface wound rinsing agent used in clinical practice. However, there are reported cases of hydrogen peroxide causing oxygen embolism in closed or semiclosed operations [4-10]. When the amount of oxygen entering the blood circulation exceeds the absorptive capacity $(40 \mathrm{ml})$, the possibility of sudden death increases significantly [11].

We report a case of oxygen embolism and myoglobinuria after the use of hydrogen peroxide irrigation during hip arthroscopy for septic arthritis.

(c) The Author(s). 2020 Open Access This article is distributed under the terms of the Creative Commons Attribution 4.0 International License (http://creativecommons.org/licenses/by/4.0/), which permits unrestricted use, distribution, and reproduction in any medium, provided you give appropriate credit to the original author(s) and the source, provide a link to the Creative Commons license, and indicate if changes were made. The Creative Commons Public Domain Dedication waiver (http://creativecommons.org/publicdomain/zero/1.0/) applies to the data made available in this article, unless otherwise stated. 


\section{Case presentation}

A 61-year-old male was admitted to a rural hospital due to right hip pain for 13 days, aggravated for 3 days. His MRI (Fig. 1) of the right hip demonstrated an effusion and synovitis in the joint. His blood tests demonstrated an elevated white blood cell $15.16 \times 10^{9} / \mathrm{L}$, neutrophil 94.6\%, C-reactive protein $126.8 \mathrm{mg} / \mathrm{L}$, erythrocyte sedimentation rate $90 \mathrm{~mm} / \mathrm{h}$ (Table 3-a). After 2 days of intravenous (IV) ceftazidime (2 g BD) he didn't improve and was transferred to our hospital. The patient has no significant medical history.

On arrival the surgeon performed an ultrasound guided right hip aspiration and $3 \mathrm{ml}$ of pus was aspirated which grew Staphylococcus aureus on culture.

The following day the patient underwent a right hip arthroscopy and joint debridement under lumbar plexus block. At the beginning of the anesthesia, the blood pressure was $138 / 80 \mathrm{mmHg}$, the heart rate was 92 beats/ min, the oxygen saturation $\left(\mathrm{SaO}_{2}\right)$ was $100 \%$, and the end-expiratory $\mathrm{CO} 2$ concentration $\left(\mathrm{etCO}_{2}\right)$ was 38 mmHg (Table 1-a).
Ceftazidime ( $2 \mathrm{~g}$ IV) was given $30 \mathrm{~min}$ prior to induction. Controlled hypotension was performed during the operation, and the blood pressure was maintained at $110 / 60 \mathrm{mmHg}$. After satisfactory anesthesia, the patient was positioned supine in traction on the operation table and sterilized routinely. Under bilateral traction, a guide needle was inserted using the lateral approach. The articular space was stretched up to $1 \mathrm{~cm}$. After the guide needle entered the articular cavity, the arthroscope was placed in the direction of the guide needle. Guided by the scope the auxiliary anterolateral portal was established and the anterior articular capsule was cut transversely to expose the acetabulum and femoral head. During the operation, a large number of abscesses were found in the articular cavity and concentrated in the acetabular fossa (Fig. 2). There was extensive synovitis around the articular capsule (Fig. 2). The surgeon debrided the hip joint thoroughly, then rinsed the joint cavity with $100 \mathrm{ml}$ of $3 \%$ hydrogen peroxide for $2 \mathrm{~min}$ and $10 \mathrm{~s}$, the joint cavity was filled with bubbles. During this process there is no outflow channel maintaining a

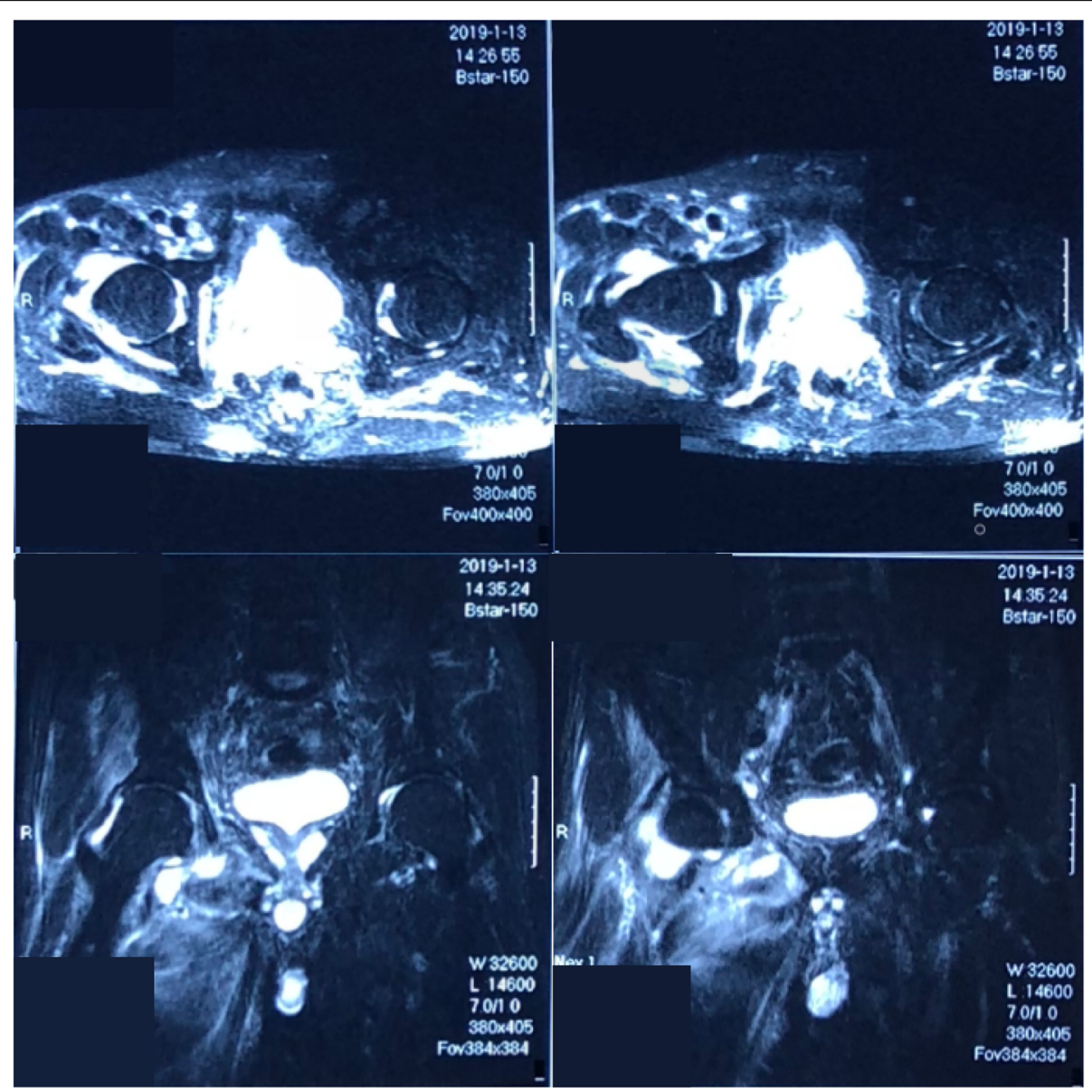

Fig. $1 \mathrm{MRI}$ of the right hip demonstrated an effusion and synovitis in the joint 
Table 1 Changes of vital signs with time

\begin{tabular}{lllll}
\hline Time & $\begin{array}{l}\text { Blood pressure } \\
\text { (mmHg) }\end{array}$ & $\begin{array}{l}\text { heart rate } \\
\text { (beats/min) }\end{array}$ & $\mathrm{SaO}_{2}$ & $\begin{array}{l}\mathrm{etCO}_{2} \\
(\mathrm{mmHg})\end{array}$ \\
\hline $\begin{array}{l}\text { (a) On anesthesia } \\
\text { induction }\end{array}$ & $138 / 80$ & 92 & $100 \%$ & 38 \\
(b) At 12:24 & $75 / 50$ & 70 & $92 \%$ & 11 \\
(c) At 12:34 & $90 / 55$ & 80 & $93 \%$ & 17 \\
(d) At 12:50 & $97 / 55$ & 80 & $97 \%$ & 29 \\
(e) At 13:00 (post op) & $90 / 50$ & 80 & $95 \%$ & $\backslash$ \\
(f) 40 4 g/ml & $100 / 50$ & 1 & $\backslash$ & $\backslash$ \\
norepinephrine 12 ml/h & & & & \\
(g) 19:00 norepinephrine & $100 / 55$ & 80 & $\backslash$ & $\backslash$ \\
at 4 ml/h & & & & \\
(h) At 19:45 (in the ICU) & $110 / 72$ & 96 & $89 \%$ & $\backslash$ \\
(i) At 09:40 Day 1 post op & $131 / 76$ & 68 & $97 \%$ & $\backslash$ \\
\hline
\end{tabular}

Table 1 Changes in vital signs over the course of surgery and during the immediate post-operative period. Hydrogen peroxide wash was undertaken arthroscopically at 12:22. (The symbol 1 ' means that there are not relevant records)

high-pressure state. No antibiotics were added to the 3\% hydrogen peroxide.

There was a transient decrease in oxygen saturation at 12:24, the heart rate slowed down and the blood pressure decreased after $1 \mathrm{~min}$. Left radial artery manometry demonstrated a blood pressure of $70 / 50 \mathrm{mmHg}$, heart rate 70 beats/min, with a drop in $\mathrm{SaO}_{2} 92 \%$ and etCO
$11 \mathrm{mmHg}$ (Table 1-b). Acute blood gas analysis showed a $\mathrm{PH}$ of 7.30 , a $\mathrm{PCO}_{2}$ of $44 \mathrm{mmHg}$, and a $\mathrm{PO}_{2}$ of $239 \mathrm{mmHg}$ (Table 2-a). Considering the possibility of pulmonary arterial oxygen embolism, $2 \mathrm{mg}$ of dopamine was injected intravenously, all hydrogen peroxide was extracted out under negative pressure and the joint cavity was washed with a large amount of isotonic saline $(18 \mathrm{~L}$ used in total throughout the operation), then the joint fluid was drained by negative pressure (Table 1-c $+\mathrm{d}$ ).

At 13:00, the operation was completed. After removing the sterile drapes, the surgeons found that there was subcutaneous crepitus in the right lower extremity, from the anterior superior iliac spine to $5 \mathrm{~cm}$ above the ankle joint, the reason for no further subcutaneous crepitus was the elastic bandage used to protect the traction area. The patient was transferred to the resuscitation room with tracheal intubation under anesthesia (Table 1-e). The blood pressure continued to fluctuate requiring norepinephrine (Table 1-f). After extubating in the resuscitation room, the patient was conscious and moving all limbs to command; the blood gas improved, however, the blood pressure required ongoing support with norepinephrine (Table 1-g, Table 2-d). He was transferred to ICU at 19:45 (Table 1-h). The circumference of the most swollen part of right thigh $(11 \mathrm{~cm}$ under the femoral trochanter) was $56 \mathrm{~cm}$, and the circumference of the

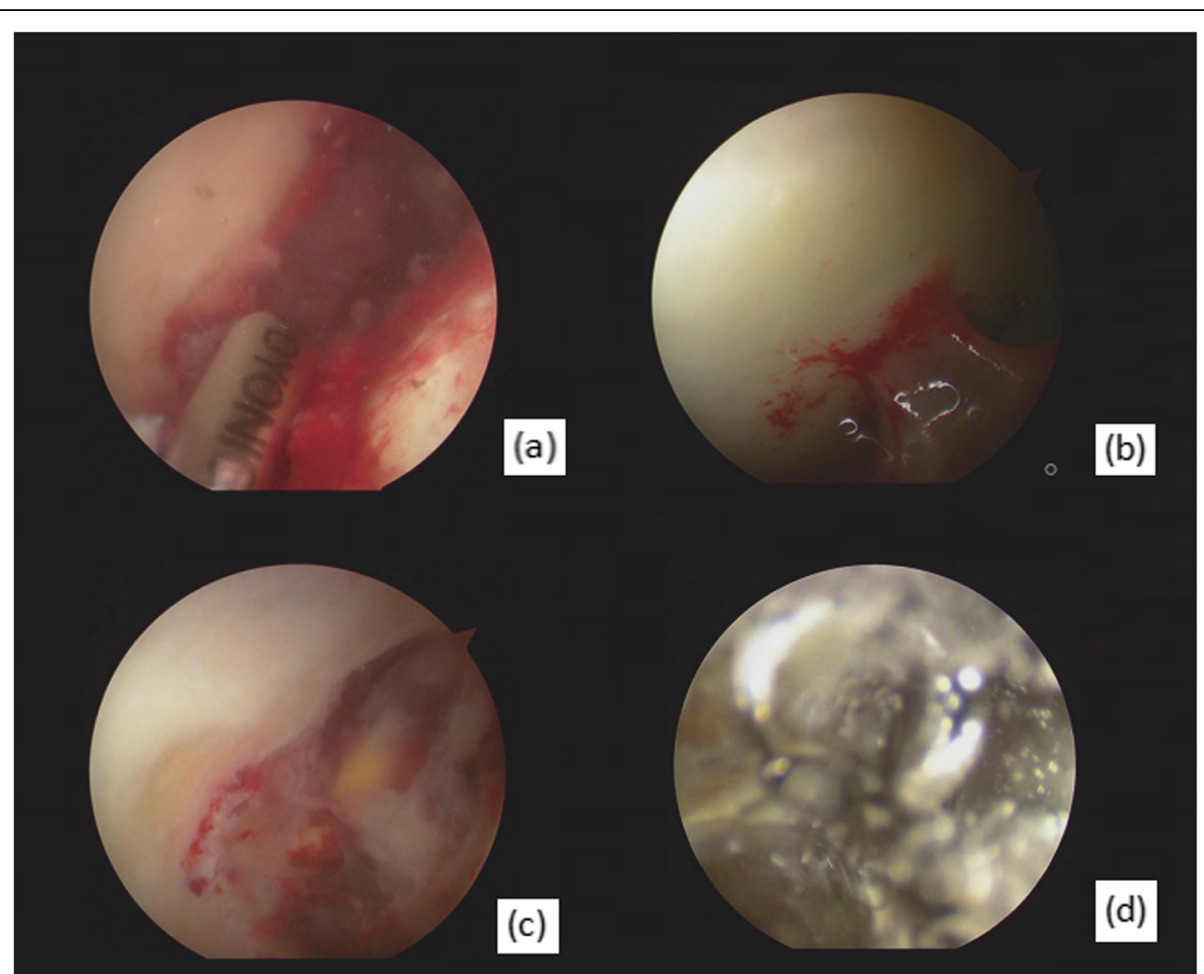

Fig. 2 Arthroscopic views revealing pyogenic moss on entry of the joint cavity (a), severe synovial and capsular inflammation around the femoral head (b), and pus collection in the oval fossa (c), The joint cavity was filled with bubbles during hydrogen peroxide rinsing (d) 
Table 2 Changes in blood gas analysis with time

\begin{tabular}{llll}
\hline Time & $\mathrm{PH}$ & $\mathrm{PCO}_{2}(\mathrm{mmHg})$ & $\mathrm{PO}_{2}(\mathrm{mmHg})$ \\
\hline (a) At 12:24 & 7.30 & 44 & 239 \\
(b) After extubating & 7.33 & 43 & 155 \\
(c) At 15:20 & 7.40 & 31 & 94 \\
(d) At 19:00 & 7.38 & 29 & 77 \\
\hline
\end{tabular}

Table 2 Changes in blood gas over the surgical period. Hydrogen peroxide irrigation at 12:22

most swollen part of the calf ( $5 \mathrm{~cm}$ from the tibial tubercle) was $34 \mathrm{~cm}$. The contralateral thigh and calf circumferences were 50 and $31 \mathrm{~cm}$ respectively.

At 19:45, the catheter drained out $800 \mathrm{ml}$ of concentrated dark urine. The ECG showed: sinus rhythm and left ventricular hypertrophy, the blood tests demonstrated: creatine kinase $17,473.1 \mathrm{u} / \mathrm{L}$, kinase isoenzymes $345.8 \mathrm{u} / \mathrm{L}$, myoglobin 11,728.5 $\mu \mathrm{g} / \mathrm{L}$, haemoglobin $106 \mathrm{~g} /$ $\mathrm{L}$, lactate dehydrogenase $567.4 \mathrm{u} / \mathrm{L}$, potassium 5.14 $\mathrm{mmol} / \mathrm{L}$, high sensitivity troponin $\mathrm{T} 56.58 \mathrm{pg} / \mathrm{ml}, \mathrm{N}$ terminal natriuretic peptide precursor $448.6 \mathrm{pg} / \mathrm{ml}$. The urinary occult blood test was strongly positive (Table 3c/Table 4-a), which was considered a result of the muscle injury caused by the hydrogen peroxide.

At 09:40 on the 1st post-operative day, the patient's vital signs stabilised (Table 1-i). He was transferred back to the general ward. There was still subcutaneous emphysema from the wound of the right thigh to the middle of the lower leg. The circumference of the right thigh was $59 \mathrm{~cm}$ and that of the calf was $34 \mathrm{~cm}$. After discussion, this patient was diagnosed with an oxygen pulmonary embolism; he received piperacillin tazobactam (Tazocin) $(4.5 \mathrm{~g}$ Q8h) intravenously for the infection.

On the 2nd day post-operatively, the patient's right thigh circumference was $54 \mathrm{~cm}$, and there was still subcutaneous crepitus. The calf circumference $(10 \mathrm{~cm}$ under the tibial tubercle) was $32 \mathrm{~cm}$. On the 5th day after operation, the patient's vital signs were stable. The right thigh circumference was $51 \mathrm{~cm}$, the calf circumference $(30 \mathrm{~cm}$ under the tibial tubercle) was $30 \mathrm{~cm}$, and the subcutaneous crepitus had resolved. The blood and urine tests were improving but had yet to normalize (Table 3-d/Table 4-b) The surgical specimens and blood cultures demonstrated Staphylococcus aureus septicemia. The patient then was treated with Tazocin plus with linezolid (0.6 g Q12h IV).

On the 12th day after operation, the blood and urine tests had recovered substantially (Table 3-e/Table 4-c). The patient was discharged without further complications.

\section{Discussion and conclusions}

In developing countries, compared with other common antiseptic agents, hydrogen peroxide is cheap and easily available. Theoretically, hydrogen peroxide can kill bacterium by destroying DNA [12], oxidizing protein and membrane lipids [13]. It can also effectively prevent the formation of bacterial biofilms [14]. Therefore, it has been widely used in our clinical practice to treat infections.

However, non-negligible risks have been found, especially in Orthopaedics. It has been reported that hydrogen peroxide can cause chondrotoxicity. It can inhibit the metabolism of normal chondrocytes, deplete the adenosine triphosphate, and reduce the synthesis of proteoglycan and hyaluronic acid in cartilage [15-17]. Hydrogen peroxide also can increase vascular endothelial permeability, pass through the cell membranes via the water channels and cause tissue and cell damage [18]. When hydrogen peroxide is used near blood vessels or organs with rich blood supplies, even traces of hydrogen peroxide $(>5 \mathrm{ml})$ can produce oxygen [19]. If the process continues, $1 \mathrm{ml}$ of hydrogen peroxide can produce $10 \mathrm{ml}$ of oxygen, therefore, it can lead to a disaster if used in a closed cavity [20]. Akuji and Chambers [21] question the evidence supporting the safety of using hydrogen peroxide during surgery. Although air embolism caused by hydrogen peroxide is rare in arthroscopic surgery, serious consequences of air embolism caused by hydrogen peroxide have been reported in other surgical fields, such as fatal ischemic brainstem lesions and pneumocephalus during spinal surgery [4], tension pneumocephalus and oxygen emboli during a high grade glioma surgery [7], portal venous gas after accidental ingestion

Table 3 Changes of blood test with time

\begin{tabular}{lllllll}
\hline Time & WBC $\left(\times 10^{9} / \mathrm{L}\right)$ & $\mathrm{Hb}(\mathrm{g} / \mathrm{L})$ & $\mathrm{N} \%$ & $\mathrm{ESR}(\mathrm{mm} / \mathrm{h})$ & $\mathrm{CRP}(\mathrm{mg} / \mathrm{L})$ & urinary OB test \\
\hline (a) Prior to arrival & 15.16 & $\backslash$ & 94.60 & 90 & 126.8 & 1 \\
(b) On admission & 14.65 & 112 & 83.40 & 94 & 180.00 & negative \\
(c) Day of surgery & 22.38 & 102 & 95.60 & $\backslash$ & $\backslash$ & strongly positive \\
(d) Day 5 post op & 17.43 & 99 & 86.60 & 97 & 175.7 & positive \\
(e) Day 12 post op & 10.39 & 97 & 80.80 & 92 & 40 & negative \\
\hline
\end{tabular}

Table 3 Changes in inflammatory markers with time. (The symbol ' 1 ' means that there are not relevant records. $N$ Neutrophil; $H b$ Haemoglobin; OB occult blood) 
Table 4 Changes of serum myocardial enzymogram with time

\begin{tabular}{llllll}
\hline Time & $\mathrm{CK}(\mathrm{u} / \mathrm{L})$ & kinase isoenzymes $(\mathrm{u} / \mathrm{L})$ & myoglobin $(\mathrm{ug} / \mathrm{L})$ & high sensitivity troponin $\mathrm{T}(\mathrm{pg} / \mathrm{ml})$ & $\mathrm{BNP}(\mathrm{pg} / \mathrm{ml})$ \\
\hline (a) Day 0 post op & $17,473.1$ & 345.8 & $11,728.5$ & 56.58 & 448.6 \\
(b) Day 5 post op & 8645.5 & 86.9 & 1747. & 15.88 & 725.2 \\
(c) Day 12 post op & 63.4 & 9.2 & 39.1 & 20.29 & 90.9 \\
\hline
\end{tabular}

Table 4 Cardiac enzyme trends immediate post operatively and over the following days. CK Creatine Kinase; BNP N-terminal natriuretic peptide precursor

of concentrated hydrogen peroxide [8], cardiac arrest during arthroplasty [9], and air embolism after irrigation of external fixator pin sites with hydrogen peroxide [10]. Based on all of its potential safety hazards, surgeons have reduced and even stopped the use of hydrogen peroxide in closed cavities.

The use of hydrogen peroxide in our hospital remains commonplace. Despite previously published reports warning against the use of hydrogen peroxide in closed cavities the uptake of new techniques and knowledge lags behind in developing countries.

In conclusion, our practice needs to be updated as evidence and experiences dictate, and hydrogen peroxide should never be used to rinse closed joint cavities.

\section{Abbreviations}

BNP: N-terminal natriuretic peptide precursor; CK: Creatine kinase; CRP: Creactive protein; ECG: Electrocardiogram; ESR: Erythrocyte sedimentation rate; etCO2: End-expiratory CO2 concentration; LDH: Lactate dehydrogenase; SaO2: Dioxy saturation; WBC: White blood cell

\section{Acknowledgements}

None. This research did not receive any specific grant from funding agencies in the public, commercial, or not-for-profit sectors.

\section{Authors' contributions}

ZWP: Participated in the treatment; collected, analyzed and interpreted the data, draft the manuscript. HL: attending doctor for the patient treatment. ZQC: collected, analyzed and interpreted the data, and draft the manuscript. WCZ: collected the data and draft the manuscript. HXL: the chief assistant at surgery, collected the data. RPD: the anesthetist at surgery, rescued the patient in operating theatre. LL: the anesthetist treated the patient in the resuscitation room. XZM: guided the treatment of this patient. DMG: revised the manuscript. TLH: the surgeon of the patient, directed how to collect the data, wrote the article. All authors have read and approved the manuscript.

\section{Funding}

Not applicable.

\section{Availability of data and materials}

The datasets used and/or analysed during the current study are available from the corresponding author on reasonable request.

\section{Ethics approval and consent to participate}

The patient signed an informed consent form.

\section{Consent for publication}

All authors agreed to publish.

Written consent has been obtained from the patient.

\section{Competing interests}

The authors declare that they have no competing interests.

\section{Author details}

${ }^{1}$ Department of Orthopaedics, the Second Xiangya Hospital, Central South University, No.139 Middle Renmin Road, Changsha 410011, Hunan, China.

2Department of Orthopaedics and Trauma, Royal Adelaide Hospital, Adelaide, Australia.

Received: 8 November 2019 Accepted: 20 January 2020

Published online: 30 January 2020

\section{References}

1. Chung WK, Slater GL, Bates EH. Treatment of septic arthritis of the hip by arthroscopic lavage. J Pediatr Orthop. 1993;13(4):444-6.

2. Bould M, Edwards D, Villar RN. Arthroscopic diagnosis and treatment of septic arthritis of the hip joint. Arthrosc J Arthrosc Relat Surg Off Publ Arthrosc Assoc N Am Int Arthrosc Assoc. 1993;9(6):707-8.

3. Blitzer CM. Arthroscopic management of septic arthritis of the hip. Arthrosc J Arthrosc Relat Surg Off Publ Arthrosc Assoc N Am Int Arthrosc Assoc. 1993;9(4):414-6.

4. Chhabra R, Pathak A, Ray P. Fatal posterior fossa pneumocephalus due to hydrogen peroxide irrigation of lumbar wound. Br J Neurosurg. 2000; 14(6):549-51.

5. Kleffmann J, Ferbert A, Deinsberger W, Roth C. Extensive ischemic brainstem lesions and pneumocephalus after application of hydrogen peroxide (H2O2) during lumbar spinal surgery. Spine J Off J North Am Spine Soc. 2015:15(4):e5-7.

6. Spiriev T, Prabhakar H, Sandu N, Tzekov C, Kondoff S, Laleva L, et al. Use of hydrogen peroxide in neurosurgery: case series of cardiovascular complications. JRSM Short Rep. 2012;3(1):6.

7. Huang C, Pik J. Tension pneumocephalus and oxygen emboli from hydrogen peroxide irrigation. J Clin Neurosci Off J Neurosurg Soc Australas. 2014;21(2):323-5.

8. Burns RA, Schmidt SM. Portal venous gas emboli after accidental ingestion of concentrated hydrogen peroxide. J Emerg Med. 2013;45(3):345-7.

9. Timperley AJ, Bracey DJ. Cardiac arrest following the use of hydrogen peroxide during arthroplasty. J Arthroplast. 1989;4(4):369-70.

10. Henley N, Carlson DA, Kaehr DM, Clements B. Air embolism associated with irrigation of external fixator pin sites with hydrogen peroxide. A report of two cases. J Bone Joint Surg Am. 2004:86(4):821-2.

11. McDonnell G, Russell AD. Antiseptics and disinfectants: activity, action, and resistance. Clin Microbiol Rev. 1999;12(1):147-79.

12. Imlay JA, Chin SM, Linn S. Toxic DNA damage by hydrogen peroxide through the Fenton reaction in vivo and in vitro. Science. 1988; 240(4852):640-2.

13. Linley E, Denyer SP, McDonnell G, Simons C, Maillard J-Y. Use of hydrogen peroxide as a biocide: new consideration of its mechanisms of biocidal action. J Antimicrob Chemother. 2012;67(7):1589-96.

14. Presterl E, Suchomel M, Eder M, Reichmann S, Lassnigg A, Graninger W, et al, Effects of alcohols, povidone-iodine and hydrogen peroxide on biofilms of Staphylococcus epidermidis. J Antimicrob Chemother. 2007;60(2):417-20.

15. Asada S, Fukuda K, Nishisaka F, Matsukawa M, Hamanisi C. Hydrogen peroxide induces apoptosis of chondrocytes; involvement of calcium ion and extracellular signal-regulated protein kinase. Inflamm Res Off J Eur Histamine Res Soc Al. 2001;50(1):19-23.

16. Asada S, Fukuda K, Oh M, Hamanishi C, Tanaka S. Effect of hydrogen peroxide on the metabolism of articular chondrocytes. Inflamm Res Off J Eur Histamine Res Soc Al. 1999:48(7):399-403.

17. Bates EJ, Johnson CC, Lowther DA. Inhibition of proteoglycan synthesis by hydrogen peroxide in cultured bovine articular cartilage. Biochim Biophys Acta. 1985;838(2):221-8. 
18. Bienert GP, Schjoerring JK, Jahn TP. Membrane transport of hydrogen peroxide. Biochim Biophys Acta. 2006;1758(8):994-1003.

19. Zimmerman GA, Lipow Kl. Pneumocephalus with neurological deficit from hydrogen peroxide irrigation. Case illustration J Neurosurg. 2004;100(6):1122.

20. Mut M, Yemisci M, Gursoy-Ozdemir Y, Ture U. Hydrogen peroxideinduced stroke: elucidation of the mechanism in vivo. J Neurosurg. 2009;110(1):94-100

21. Akuji MA, Chambers DJ. Hydrogen peroxide: more harm than good? $\mathrm{Br} J$ Anaesth. 2017;118(6):958-9.

\section{Publisher's Note}

Springer Nature remains neutral with regard to jurisdictional claims in published maps and institutional affiliations.

Ready to submit your research? Choose BMC and benefit from:

- fast, convenient online submission

- thorough peer review by experienced researchers in your field

- rapid publication on acceptance

- support for research data, including large and complex data types

- gold Open Access which fosters wider collaboration and increased citations

- maximum visibility for your research: over $100 \mathrm{M}$ website views per year

At BMC, research is always in progress.

Learn more biomedcentral.com/submissions 